\title{
CHARACTERIZATION OF CARBOFURAN BOUND RESIDUES AND THE EFFECT OF AGEING ON THEIR DISTRIBUTION AND BIOAVAILABILITY IN THE SOIL OF A SUGAR BEET FIELD IN NORTH-WESTERN MOROCCO
}

\author{
MOHAMED BENICHA ${ }^{1, *}$, RACHID MRABET ${ }^{2}$, and AMINA AZMANI \\ ${ }^{1}$ Pesticide Residues Laboratory, Regional Agricultural Research Center of Tangier, National Agricultural Research Institute, \\ 78 Bd Mohamed Ben Abdellah, 90010 Tangier, Morocco \\ 2 Scientific Division, National Agricultural Research Institute, Rabat, Morocco \\ ${ }^{3}$ Department of Chemistry, Faculty of Science and Technology, University Abdel Malik Essaadi, Tangier, Morocco \\ * Corresponding author: mbenicha@gmail.com
}

\begin{abstract}
This study was undertaken to investigate distribution, fractionation, bioavailability and remobilization characteristics of bound soil-aged carbofuran and the effect of ageing in clay soil in a typical field of sugar beet at Loukkos in northwest Morocco. Results indicate that initially there were high levels of bound residues (BR) in the humin fraction, which decreased with incubation time and ageing of the BR. While in the fulvic and humic acid fractions, the amount of BR increased with the ageing of the BR and occurred predominantly $(60 \%)$ in the fulvic acid fraction. The possibility of the mineralization and release of BR with ageing was studied using fresh soil and an incubation period of 90 days. The results indicate that the ageing of the residues have a great influence on the remobilization and mineralization rates of carbofuran BR; 9.45 to $14.90 \%$ of the total BR was released as extractable residues, and 1.95 to $4.15 \%$ was mineralized depending on the age of the residues in soil and the soil-aged carbofuran $\mathrm{BR}$. The incorporation of the residues in the humin fraction is considered to be a threat to the environment. On the other hand, the clear prevalence of residues in the fulvic and humic acid fractions, may have an important effect on their bioavailability and movement in soil. Moreover, the re-extractability of BR could pose a potential environmental risk. Consequently, the $\mathrm{BR}$ remobilized must be taken into account when assessing for registration processes the environmental risk of pesticides persisting in soils.
\end{abstract}

Keywords: aging, carbofuran, bound residues, ${ }^{14} \mathrm{C}$-technique, extractability, soil organic matter fractionation

doi: $10.14712 / 23361964.2016 .9$

\section{Introduction}

Previous investigations show that pesticides bind almost irreversibly with soil constituents, including organic compounds, resulting in the formation of non-extractable bound residues (Führ 1987; Calderbank 1989; Khan and Behki 1990; Gevao 2000; Nowak et al. 2011; Liu et al. 2013; Kästner et al. 2014). These chemical entities are defined as pesticide residues that are not extractable using current methods. They are not extractable using methods that do not significantly change their nature (Roberts et al. 1984; Fuhr et al. 1998).

Because of the difficulty of extracting these residues using conventional analytical methods total pesticide residues tend to be underestimated (Führ 1982; Khan 1982; Calderbank 1989). The use of molecules radiolabelled with ${ }^{14} \mathrm{C}$ has revealed that pesticides remain firmly bound to the soil matrix. This is the result of changes in the stabilization process of the sorption phenomena from weak to strong adsorption sites and diffusion and sequestration or entrapment by sites, during which pesticides and their degradation products become increasingly more stable and less available (Bertin and Schiavon 1989; Senesi 1992; Loiseau 2001; Barriuso and Benoit 2006).

As summarized in Gevao et al. (2003), these residues become increasingly unavailable to the biota, less toxic and less likely to desorb from humic substances over time. For the environment this reduction in bioavailability and accessibility is beneficial. However, there might be processes, which cause an irreversible release of sorbed residues over time (Khan and Ivarson 1981, 1982; Yee et al. 1985; Barriuso et al. 2004). The extent of the reversibility between unavailable and available forms of bound residues (BR) is likely to play an important role in the long-term fate of pesticides (bioavailability) (Barriuso et al. 2008).

Two main mechanisms are involved in BR formation: (i) Covalent(s) binding between pesticides or their degradation products and soil constituents; (ii) physical entrapment of the compound or its degradation products in soil matrices (Bertin and Schiavon 1989; Calderbank 1989; Bollag et al. 2002). Regardless of the mechanism, soil organic matter is involved in their formation.

The extent of the formation of BRs varies depending on the compound, but it may result in a significant part of the residues remaining in the soil, ranging, in general, from 7 to $95 \%$ of the dose initially applied (Bollag and Loll 1983; Führ 1987; Calderbank 1989).

\section{Bioavailability of Bound Residues}

Bound pesticide residues may give rise to a number of concerns. Among these are questions of bioavailability, runoff, leaching into natural waters and potential longterm effects on soil quality. 
On the other hand, BR formation can be regarded as a stabilization process leading to an increase in the persistence of pesticides in soils. However, the formation of BRs pose problems concerning their fate and potential long term risks (Kacew et al. 1996; Alexander 2000). From an environmental point of view, it appears that their immobilization is advantageous and may be regarded as a process contributing to reducing the risk of these residues polluting soil and water (Calderbank 1989; Barriuso and Benoit 2006; Barriuso et al. 2008). Because of their possible release/remobilization by a variety of processes (Gevao et al. 2005) these residues can become potentially bioavailable in the future and may then constitute a threat to soil quality (Burauel and Führ 2000) and sensitive crops (Novak et al. 1995; Scheunert and Reuter 2000; Gevao et al. 2001; Han et al. 2009) and subsequently contribute to diffuse pollution (Dec et al. 1990; Barriuso et al. 2008) and contaminate drain and groundwater resources (Khan 1982; Capriel et al. 1985).

For the environmental risk assessment, it is essential to determine whether the bound residues are permanently retained or gradually released into the soil solution and therefore become again bioavailable for plants, living organisms and are likely to contaminate water resources. On the other hand, study of the localization of sites of BRs in soil organic fractions is of great interest as long as it is used to estimate the risk of residues being mobilized. It has been the subject of a number of studies (Nichiolls 1988; Bertin and Schiavon 1989). Khan and Hamilton (1980) demonstrate that bound residues are located in 3 major fractions of soil organic matter, i.e. fulvic acid (FA), humic acid (HA) and humin (H).

Carbofuran 2,3-dihydro-2,2-dimethyl-7-benzofuranyl methylcarbamate) is among the most widely used carbamate insecticide and nematicide worldwide due to its broad spectrum of effectiveness against a wide range of insects and pests on several crops, including wheat, sugar beet, sugar cane, corn, rice, potato, cotton, sunflower, etc. (Chapalamadugu and Chaudhry 1992; Jaramillo et al. 2000; Ezzahiri et al. 2015). As a result, it has attracted more attention as an alternative to the more persistent and highly toxic organochlorine insecticides (Goad et al. 2004; Saxena et al. 2013).

However, despite its efficacy as an agricultural pesticide, Furadan ${ }^{\circ}$ has been restricted or banned in many countries, including the USA and Canada (Erwin 1991; Agriculture Canada 1993). However, in Morocco, as in many countries (Gnanavelrajah and Kandasamy 2012; Otieno and Schramm 2012; Khairatul et al. 2013), it is still used in large amounts, particularly in sugar beet and tomato crops, against many insects, root worms and earthworms (Ezzahiri et al. 2015).

Experiments on the long-term fate of ${ }^{14} \mathrm{C}$-labeled pesticides in soils are rarely conducted. There are no studies on the effect of old carbofuran bound residues on remobilization and mineralization of long term-aged ${ }^{14} \mathrm{C}$-labelled pesticide residues, which are necessary for a better understanding of the remobilization of carbofuran bound residues under changing abiotic conditions. Therefore, the present study investigated the distribution of carbofuran BR in soil, their biodegradation and the influence of ageing on their fate in soil in at Loukkos, an important agricultural area in north western Morocco, characterized by intensive agriculture mainly consisting of horticultural cultures, sugar beet, sugar cane, etc. According to the national statistics the area under sugar beet $(65,000 \mathrm{ha})$ (Doukkali et al. 2009) is annually sprayed with about 1300 tons of this insecticide, with more than 100 tons applied at Loukkos (5140 ha). With increase in population and increase sugar consumption, currently estimated at $34 \mathrm{~kg} /$ person/year (Bouziane 2011), efforts are being made to intensify sugar beet production to attain national self-sufficiency in sugar production, which is among the recommendations of the Green Moroccan Plan, a new government agricultural development strategy (ADA 2009). On the other hand, although frequently invoked to explain the decreases in pesticide degradation with time (e.g. Boivin et al. 2004; Amellal et al. 2006; Kästner et al. 2014), the relationship between the ageing of the bound residues of pesticides and their biodegradability by re-incubation of differently aged BR in fresh soil has been poorly investigated (Lerch et al. 2009).

Understanding the behaviour of bound residues of carbofuran in the environment, is essential for determining the long-term fate and significance of this potential reservoir of contaminants and to develop strategies for remediation and prevention of adverse effects on the environment caused by using it to treat fields of sugar beet.

The specific objectives of this work were (i) to study the distribution of bound residues of ${ }^{14} \mathrm{C}$-carbofuran in different organic matter fractions of soil, (ii) to evaluate the potential mineralization of carbofuran bound residues in soil, (iii) to estimate their risk of being remobilized as a result of ageing, and finally (iv) to quantify the effect of ageing on the distribution of carbofuran BR in the different organic matter fractions in soil and their bioavailability in soil, in order to improve risk assessment.

\section{Materials and Methods}

\section{Soil Samples}

The soil samples used in this study were obtained from a previous study on the dissipation of ${ }^{14} \mathrm{C}$-carbofuran over a period of 168 days using soil columns (Benicha and Azmani 2005). We used different aged soil samples (from 7 to 168 day samples: the compound had aged for 7 to 168 days in soil) which contained ${ }^{14} \mathrm{C}$-carbofuran BR residues. The BR soil samples were used after complete soxhlet extraction using methanol, air drying, crushing and homogenizing. Samples of fresh soil were also collected from around the perimeter of Loukkos. Its physical and chemical characteristics are presented in Table 1. 
Table 1 Physical and chemical characteristics of the soil used.

\begin{tabular}{|c|c|c|c|c|c|c|c|}
\hline $\begin{array}{c}\text { pH } \\
\text { (water) }\end{array}$ & $\begin{array}{c}\text { pH } \\
\text { (KCl) }\end{array}$ & $\begin{array}{c}\text { Total N } \\
(\mathbf{\%})\end{array}$ & $\begin{array}{c}\text { Organic } \\
\text { Matter (\%) }\end{array}$ & $\begin{array}{c}\text { Clay (\%) } \\
(<\mathbf{2} \mathbf{~ m m})\end{array}$ & $\begin{array}{c}\text { Silt (\%) } \\
(\mathbf{2}-\mathbf{5 0} \mathbf{~ m m})\end{array}$ & $\begin{array}{c}\text { Sand (\%) } \\
\mathbf{( 5 0 - 2 0 0} \mathbf{~ m m})\end{array}$ & $\begin{array}{c}\text { CEC } \\
(\mathbf{m e q} / \mathbf{1 0 0})\end{array}$ \\
\hline 7.8 & 7.3 & 0.2 & 2.1 & 50.2 & 35.6 & 14.2 & 43.4 \\
\hline
\end{tabular}

\section{Distribution of Bound Residues in Different Organic Matter Fractions in the Soil}

To localize ${ }^{14} \mathrm{C}$-carbofuran $\mathrm{BR}$ in soil, we fractionated organic matter using Thibaud et al. (1983) method. The soil was mixed with $0.1 \mathrm{~N} \mathrm{NaOH}$ and $0.1 \mathrm{M}$ sodium pyrophosphate $\left(\mathrm{Na}_{4} \mathrm{P}_{2} \mathrm{O}_{7}\right)$ solutions and shaken for 1 hour. The mixture was then centrifuged at $4000 \mathrm{rpm}$ for $20 \mathrm{~min}$. The precipitate obtained is the humin $(\mathrm{H})$ fraction. Alkaline extracts contain humic (HA) and fulvic (FA) acids. HA was precipitated by adjusting the $\mathrm{pH}$ solution to 2 with $\mathrm{H}_{2} \mathrm{SO}_{4}$. After $30 \mathrm{~min}$ at $4{ }^{\circ} \mathrm{C}$, solutions were centrifuged at $4000 \mathrm{rpm}$ for $20 \mathrm{~min}$ and the supernatant containing FA was recovered. Precipitated HA were dissolved in $10 \mathrm{ml}$ of $0.1 \mathrm{~N} \mathrm{NaOH}$ and the radioactivity of $\mathrm{HA}$ and FA was measured using a Liquid Scintillation Counter (LSC). HA fraction was quantified using a Biological Material Oxidizer (BMO) and the ${ }^{14} \mathrm{CO}_{2}$ formed was quantified (LSC).

\section{Mineralization and Bio-Release of Carbofuran Bound Residues}

Extracted soil sample $(50 \mathrm{~g})$ was mixed with $50 \mathrm{~g}$ of the same type of soil (freshly collected and sieved to $2 \mathrm{~mm}$ ) and placed in standard biometric flasks at room temperature. $20 \mathrm{ml}$ ethanolamine (scintillation grade) was placed in the side arm of the flasks to trap the ${ }^{14} \mathrm{CO}_{2}$ released. Distilled water was added to the mixture in order to maintain humidity equivalent to $60 \%$ of water holding capacity. The flasks were then closed and the humidity controlled and adjusted periodically by weighing the flasks. The experiment was carried out over a period of 90 days. The samples were collected, in triplicate, after 0, 30, 60 and 90 days of incubation. The ${ }^{14} \mathrm{CO}_{2}$ released was quantified (LSC) and the soil in each sample was soxhlet extracted in methanol to determine the quantity of residue rendered extractable. The new extracted soil samples were then air-dried and combusted, using BMO to determine amount of residue still bound to the soil.

\section{Determination of Bound and Total Residues}

The determination of total and bound residues was carried out using a Biological Material Oxidizer (Harvey OX600). The ${ }^{14} \mathrm{CO}_{2}$ obtained after combustion of a soil sample $(10 \mathrm{~g})$ at high temperatures $\left(900{ }^{\circ} \mathrm{C}\right)$ for $5 \mathrm{~min}$, was trapped in scintillation grade ethanolamine $(10 \mathrm{ml})$ and the radioactivity determined by measuring $1 \mathrm{ml}$ of the solution in the liquid scintillation counter.

\section{Determination of Extractable Residues}

$50 \mathrm{~g}$ (dry weight basis) soil samples were extracted in a soxhlet extraction apparatus with methanol for $4 \mathrm{~h}$ (5-6 cycles/h). The procedure was continued until the extracts were no longer radioactive. Methanol was concentrated to $10 \mathrm{ml}$ in a Rotavapor, Buchï, Switzerland at $30{ }^{\circ} \mathrm{C}$ and then $1 \mathrm{ml}$ methanol extract was mixed with toluene based scintillator and radio assayed.

\section{Radioactivity Measurement}

Radioactivity was measured using a liquid scintillation counter Packard Tricarb 1100 after a cocktail xylene-based solution containing PPO (2,5-diphenyl oxazole), POPOP (1.4-bis/2-(5-phenyloxazolyl)benzene) and naphthalene was added to the sample. The internal standard was used to correct for any quenching effect.

\section{Results and Discussion}

\section{Distribution of Carbofuran Bound Residues in Soil Organic Matter}

The distribution of carbofuran bound residues in the different organic fractions in soil determines their bioavailability and fate. The fractionation of the organic matter revealed that bound residues were present in all the fractions. The result showed that initially the bound residues were mainly in the humin fraction with more than $50 \%$ of the BRs. With ageing, however, these residues were released from the humin fraction and incorporated into humic fractions, i.e. FA and HA, with most in the FA fraction (Fig. 1). Thus, after 168-days of incubation (aged sample) large amounts of these bound residues were incorporated in the FA fraction with $42.03 \%$ as against $28.96 \%$ and $29.01 \%$, respectively, for the $\mathrm{H}$ and HA fractions, whereas after 7 days of incubation, FA contained only $26.43 \%$ as against $22.94 \%$ and $50.63 \%$, respectively, for the HA and $\mathrm{H}$ fractions.

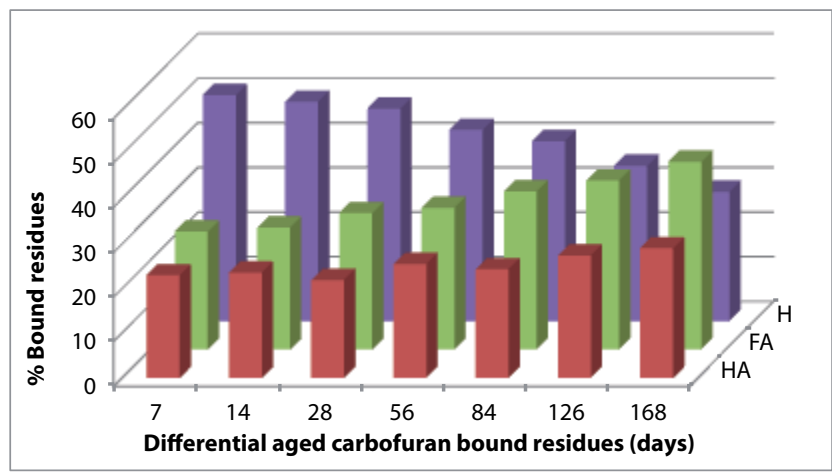

Fig. 1 The percentage distribution of different aged carbofuran bound residues in the different organic matter fractions in soil (FA: fulvic acid, HA: humic acid, H: humin). 
Similar results are reported in the literature. After 20 days of incubation of carbofuran in a clay-loam soil, the FA fraction contains $44 \%$ of the bound residues, followed by HA with $38 \%$ and humin with $20 \%$ (Hussain et al. 1986). Lee and Park (1995) report that the non-extractable carbofuran residues are mainly located in soil organic matter in the order FA $>\mathrm{H}>\mathrm{HA}$. Carbofuran non-extractable bound residues in the humin soil organic fraction ranged from 52 to $55 \%$, with FA containing from 32 to $39 \%$ and HA from 9 to $11 \%$ of the total BR (Lee et al. 1987).

Prevalence of BR in the FA fraction is also reported for other pesticides. Khan and Hamilton (1980) found that the residues of prometryn in the $\mathrm{H}$ fraction move over time into the FA and HA fractions. On the other hand, Barriuso et al. (1991) report that Atrazine residues are first bound to FA and finally to humin.

The high accumulation of residues in water-soluble fulvic and humic acids (74.04\%) has important environmental consequences since it is not only available to plants, but also for soil and aquatic organisms. Lewandowska (2004) report that residues of 2,4-D bound in the soil are available for wheat plants. Most radioactive residues detected in the soil are in the water-soluble FA fraction. Therefore, these residues are available not only for plants, but also for soil and aquatic organisms. Khan (1982), Capriel et al. (1985), Bertin and Scaviona (1989) and Andreux et al. (1991), who chemically fractioned the soil organic matter, report that the FA content of soil plays an important part in the initial rapid immobilization of pesticides. This is also reported by Andreou et al. (2009) who records a great association with and enrichment of the FA fraction of the organic carbon in soil determining the distribution of BR of isoproturon, diazinon and cypermethrin pesticides. Khan (1982) and Lewandowska and Weymann (2002) consider that these residues of atrazine as potentially available for plants, soil and water fauna.

The abundance of carbofuran bound residues in FA is probably related to interactions with the polar groups that abundantly occur in the FA fraction, as suggested by Loiseau et al. (2002) for atrazine bound residues.

\section{Bioavailability of Carbofuran Bound Residues}

The bioavailability of carbofuran bound residues is presented in Fig. 2. This shows that the re-extractable residues ranged from 9.45 to $15 \%$ of the total amount, while 1.95 to $4.15 \%$ of the total bound residues were mineralized ( ${ }^{14} \mathrm{CO}_{2}$ release) depending on the incubation time and ageing of $\mathrm{BR}$ in the soil.

The results indicate a significant increase in BR extractability with incubation time. For the 7-day sample, $9.45 \%$ of the residues were extractable and after three months it was $14.90 \%$ (Fig. 2). The same tendency was recorded for the mineralization rate. For the same 7-day sample, $1.95 \%$ were mineralized after one month and increased to $4.15 \%$ after three months of incubation.

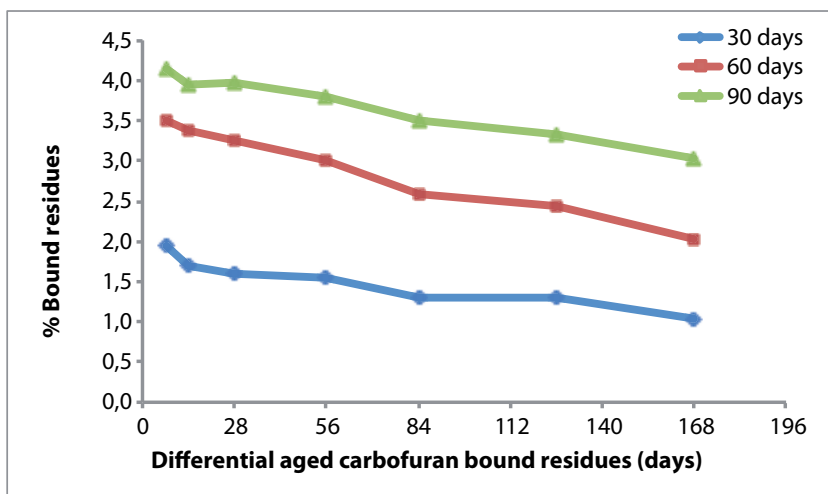

Fig. 2 Release of different aged ${ }^{14} \mathrm{C}$-carbofuran bound residues with incubation time (Re-extractability of carbofuran bound residues).

On the other hand, there was a reduction in the carbofuran BR that could be extracted from soil samples with ageing. Extractability of the carbofuran BR decreased with ageing, to $10.6 \%$ for the 168 -day sample compared to $14.9 \%$ for the 7 -day sample. However, the longer the $\mathrm{BR}$ is incubated with fresh soil the greater the increase in the extractability of BR (from 1 month to 3 months). At the end of the third month of ageing, methanol soxhlet extracts of the 7-day sample were $9.45 \%, 11.35 \%$ and $14.90 \%$ of the aged carbofuran BR, for 1,2 and 3 months respectively, while it was only $6.39 \%, 8.80 \%$ and $10.60 \%$ for the 168-day sample for the same periods.

This gradual decrease in the release of BR with ageing is probably due to the fact that $\mathrm{BR}$ formed immediately after the application of carbofuran (7 and 14 days samples) are released more quickly than those that form after a long term interaction with the soil. The same tendency was recorded for the mineralization rate of BRs; a gradual decrease with age. This gradual decrease with age of both re-extractable and mineralized quantities, could be due to the fact that the BRs become more stable the longer they are in the soil. These findings support the results on the sorption of carbofuran by soil (Benicha and Azmani 2005); their break down becomes increasingly difficult with time due to the interactions with soil components, with which the molecule becomes progressively more tightly bound, or entrapped in, the organic matrix and correspondingly more stable and less bioavailable (Ahmad et al. 2004; Barraclough et al. 2005) (ageing process).

Andrea and De Wiendl (1995) report the same for lindane with the formation and bio-release of lindane BR varying depending on soil type and ageing of the compound in the soil. Johnson et al. (1999) show that a significant reduction in atrazine BR extractability occurs with ageing. They report that extractability of BR decreases from $96 \%$ after 1 week to $66 \%$ after 3 months of ageing. Nakagawa et al. (2000) report a small release of up to $3.5 \%$ of ${ }^{14} \mathrm{C}$-atrazine $\mathrm{BR}$ from soil following the addition of an inoculum of microorganisms. Nam and Kim (2002) report a decline in the bioavailability of PAH with increase in residence time. 
BR Mineralization rates were low and did not exceed $4.15 \%$ and declined with age (from 7 to 168 -days). Their re-extractability rates however, were significantly higher, up to $15 \%$ after 90 days incubation (7-day sample). This suggests that microorganisms initially release the BR by breaking down bonds between molecules of the insecticide and the soil matrix, then degrade and mineralize them for use as a nutrient source (Ladd 1989; Khan and Behki 1990; Hayar 1997).

Results of Khan and Behki (1990) show that 30-35\% of BR of atrazine can be extracted from soil inoculated with fresh soil after 83 days. Gevao et al. (2001) also report that the re-extractability of atrazine $\mathrm{BR}$ is of the same order (24\% of BR). Khan and Ivarson (1981) report a release of $27 \%$ of the BR of prometryn by soil microorganisms after 22 days of incubation of soil containing BR associated with fresh soil. They report, however, that the evolution of ${ }^{14} \mathrm{CO}_{2}$ during this period was negligible. For the same pesticide incubated in another type of soil Khan and Ivarson (1982) report the release of 25-30\% of BR after 28 days of incubation with fresh soil. They report a low mineralization rate, which indicates that the breakdown of the aromatic ring of the product is a minor reaction. Roberts and Standen (1981) show that 25-40\% of cypermethrin residues are mineralized after incubation of soil BR with fresh soil. Nakagawa et al. (2000) report that ${ }^{14} \mathrm{C}$-atrazine $\mathrm{BR}$ is released from soil after the addition of an inoculum of microorganisms but very little ${ }^{14} \mathrm{CO}_{2}$ was produced: less than $0.8 \%$.

Our results also show that mineralization rates decrease with ageing of carbofuran BR. This could be explained by the fact that old BRs are very tightly bound to soil and very stable. These results confirm those obtained by others in that ageing reduces the mineralization of pesticides (Chung and Alexander 1998; Regitano et al. 2006). Hatzinger and Alexander (1995) report that mineralization of phenanthrene and 4-nitrophenol in soils decreases with ageing, which also increases the resistance of phenanthrene to biodegradation and extraction. Alexander (2000) report that laboratory tests confirm

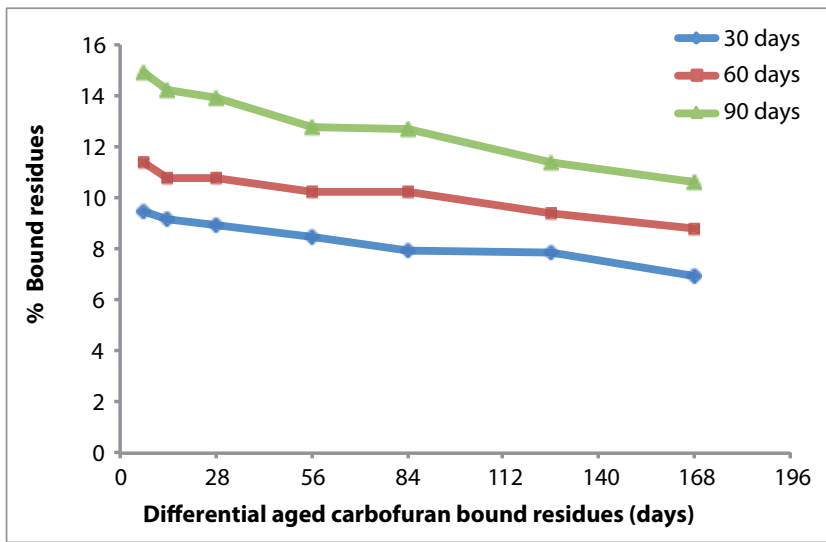

Fig. 3 Mineralization of different aged ${ }^{14} \mathrm{C}$-carbofuran bound residues with incubation time (Emission of ${ }^{14} \mathrm{CO}_{2}$ ). the lower availability to microorganisms of aged than of unaged compounds in different soils. The bioavailability to microorganisms decreases with time. Field ageing also diminishes the availability to microorganisms of many pesticides (Scribner et al. 1992; Weissenfels et al. 1992). Nam and Kim (2002) report that mineralization rates of phenanthrene aged in the humin-mineral fraction significantly decreased with time.

\section{Conclusions}

This study investigated the fate of carbofuran BR and the influence of ageing on the extent to which they are bound into organic matter fractions and their bioavailability. The distribution experiment revealed the presence of substantial amounts of carbofuran BR in water-soluble soil fractions (FA and HA). As a result, residues in this fraction are more bioavailable and thus their movement in soil constitute an environmental risk. On the other hand, their bioavailability (possibility of remobilization) increases when fresh soil is added, with re-extractability up to $15 \%$ and a mineralization rate of $4.15 \%$ over 90 days. This release of part of the residues can be a source of environmental pollution. The results also show that ageing has an effect on mineralization and extractability of carbofuran BR; the older the BR, the more difficult their release and mineralization. This is important information for environmental management and environmental risk assessment of pesticides. Therefore, the formation of bound pesticide residues in soil should be taken into account when assessing risk of applying chemicals to soils.

\section{Acknowledgements}

The authors gratefully acknowledge financial support for this work from the International Atomic Energy Agency under TCP project MOR/5/023 and also Dr. S.M.A.D. Zayed, from National Research Centre, Dokki, Cairo Egypt, for his help in experimental protocols.

\section{REFERENCES}

ADA (2009) Agence pour le développement agricole, Région de Tanger-Tétouan, cultures sucrières (Agricultural Development, Agency, Region of Tangier-Tetouan, sugar crops). www.ada .gov. Accessed 2 February 2014.

Agriculture Canada (1993) Special Review of Carbofuran Insecticide: Effects on Avian Fauna and Value to Agriculture. Direction générale, Production et inspection des aliments, Direction de l'industrie des produits végétaux Ottawa, Ontario.

Ahmad R, Kookana RS, Megharaj M, Alston AM (2004) Aging reduces the bioavailability of even a weakly sorbed pesticide (carbaryl) in soil. Environ Toxicol Chem 23: 2084-2089.

Alexander M (2000) Aging, Bioavailability, and Overestimation of Risk from Environmental Pollutants. Environ Sci Technol 34: 4259-4265. 
Andrea M De M, Wiendl FM (1995) Formation and bio-release of bound residues of pesticides in two Brazilian soils. I. LINDANE. Pesquisa Agropecuaria Brasileira. Brasilia 30: 687-694.

Amellal S, Boivin A, Ganier CP, Schiavon M (2006) Effect of ageing on mobility and sequestration of phenanthrene in an agricultural soil. Agronomy Sust Develop 26: 269-275.

Andreou K, Jones K, Semple K (2009) Occurrence of pesticide non-extractable residues in physical and chemical fractions from two natural soils. Geophysical Research Abstracts 11: 2009-6221.

Andreux F, Schiavon M, Bertin G, Portal JM, Barriuso E (1991) The usefulness of humin fractionation methods in studies about the behaviour of pollutants in soils. Toxicol Environ Chem 31/32: 29-38.

Akhtar MH, Khan SU, Kacew S (1992) Consequences Bioavailability of Bound Pesticide Residues and Potential Toxicologic Proc Soc Exp Biol Med 199: 13-21.

Barriuso E, Benoît P (2006) State-of-the-art review on bound residues. Report DL\#5 of the FP6 EU-funded FOOTPRINT project. www.eu-footprint.org. Accessed 4 March 2014.

Barriuso E, Schiavon M, Andreux F, Portal JM (1991) Localization of atrazine non-extractable (bound) residues in soil size fractions. Chemosphere 12: 1131-1140.

Barriuso E, Koskinen WC, Sadowsky MJ (2004) Solvent extraction characterization of bioavailability of atrazine residues in soils. J Agric Food Chem 52: 6552-6556.

Barriuso E, Benoit P, Dubus IG (2008) Formation of pesticide nonextractable (bound) residues in soil. Magnitude, controlling factors and reversibility. Environ Sci Technol 42: 1845-1854.

Benicha M, Azmani A (2005) Contribution à l'Etude de l'adsorption et de la désorption du carbofuran dans un sol argileux du loukkos. Al Awamia 116: 67-88.

Bertin G, Schiavon M (1989) Les résidus non extractibles de produits phytosanitaires dans les sols. Agronomie 9: 117-124.

Bollag J-M, Loll MJ (1983) Incorporation of xenobiotics into soil humin. Experientia 39: 1221-1231.

Bollag J-M, Strynar M, Ahn MY, Dec J (2002) Characterization of enzymatic or abiotic immobilization of xenobiotics in soil. In: Violante A, Huang PM, Bollag J-M, Gianfreda L (eds) Developments in Soil Science, volume 28B, pp. 289-299.

Bouziane M (2011) Le marché marocain du sucre. Pack info 95: 52-53.

Burauel P, Führ F (2000) Formation and long-term fate of non-extractable residues in outdoor lysimeter studies. Environ Pollut 108: 45-52.

Calderbank A (1989) The occurrence and significance of bound pesticide residues in soil. Rev Environ Cont Toxicol 108: 71-103.

Carpriel P, Haisch A, Khan SU (1985) Distribution and Nature of Bound (Nonextractable) Residues of Atrazine in a Mineral Soil Nine Years after the Herbicide Application. J Agric Food Chem 33: $567-569$.

Chung NH, Alexander M (1998) Differences in sequestration and bioavailability of organic compounds aged in dissimilar soils. Environ Sci Technol 32: 855-860.

Chapalamadugu S, Chaudhry GR (1992) Microbial and biotechnological aspects of metabolism of carbamates and organophosphates. Crit Rev Biotech 12: 357-389.

Dec J, Shuttleworth KL, Bollag J-M (1990) Microbial release of 2,4-dichlorophenol bound to humic acid or incorporated during humification. J Envir Quality 19: 546-551.

Dec J, Bollag J-M (1988) Microbial release and degradation of catechol and chlorophenols bound to synthetic humic acid. Soil Sci Soc Am J 52: 1366-1371.
Doukkali MR, Redani L, Lebailly P (2009) Gestion intégrée des ressources en eau et en sol et durabilité des systèmes de cultures en zones méditerranéennes, Filière sucrière et Valorisation des Ressources, Symposium International AGDUMED 2009, Agriculture durable en méditerranée, Rabat, 14-16 Mai.

Erwin NW (1991) Carbofuran and bird kills: regulation at a Snail's Pace. J Pestic Reform 11: 15-17.

Ezzahiri B, Bouhache M, Mihi M, Erraki I (2015) Index Phytosanitaire Maroc. Association Marocaine de Protection des Plantes (ed), Rabat, Morocco.

Führ F (1982) Fate of herbicide chemicals in the agricultural environment with particular emphasis on the application of nuclear techniques. IAEA-SM-263/32. In: Agrochemicals: fate and food and the environment. Proceeding of a symposium, Rome, 7-11 June 1982. International Atomic Energy Agency, Vienna, pp. 99-111.

Führ F (1987) Nonextractable pesticide residues in soil. In: Greenhalgh R, Roberts T (eds) Pesticide science and biotechnology, Blackwell's Scientific Publications, Oxford, United Kingdom, pp. 381-389.

Führ F, Ophoÿ H, Burauel P, Wanner U, Haider K (1998) Modification of the definition of bound residues. In: Senate Commission for the Assessment of Chemicals Used in Agriculture (ed) Pesticide bound residues in soil, volume 2, Wiley-VCH, DFG, pp. 175-176.

Gevao B, Semple KT, Jones KC (2000) Bound pesticide residues in soils: a review. Environ Pollut 108: 3-14.

Gevao B, Mordaunt C, Piearce TG, Semple KT, Jones KC (2001) Bioavailability of non-extractable (bound) pesticide residues to earthworm. Environ Sci Technol 35: 501-507.

Gevao B, Jones KC, Semple KT, Craven A, Burauel P (2003) Nonextractable pesticide residues in soil. Environ Sci Technol 1: 139-144.

Gevao B, Jones KC, Semple KT (2005) Formation and release of non-extractable C-14-Dicamba residues in soil under sterile and non-sterile regimes. Environ Pollut 133: 17-24.

Gnanavelrajah N, Kandasamy T (2012) Carbofuran adsorption, leaching and accumulation in edible tissues in three selected soils in tropics. American-Eurasian J Agric Environ Sci 12: 1475-1478.

Goad R, Goad J, Atieh B, Gupta R (2004) Carbofuran-induced endocrine disruption in adult male rats. Toxicol Mech Methods 14: 233-239.

Han A, Yue L, Li Z, Wang H, Wang Y, Ye Q, Lu L (2009) Plant availability and phytotoxicity of soil bound residues of herbicide ZJ0273, a novel acetolactate synthase potential inhibitor. Chemosphere 77: 955-961.

Hatzinger PB, Alexander M (1995) Effect of aging of chemicals in soil on their biodegradability and extractability. Environ Sci Technol 29: 537-45.

Hayar S, Munier-Lamy C, Chone T, Schiavon M (1997) Physicochemical versus microbial release of ${ }^{14} \mathrm{C}$-atrazine bound residues from a loamy clay soil incubated in laboratory microcosms. Chemosphere 34: 2683-2697.

Hussain A, Azam F, Malik KA (1986) Bound residues of ${ }^{14} \mathrm{C}-\mathrm{Car}-$ bofuran in soil. In: Quantification, nature, and bioavailability of bound ${ }^{14} \mathrm{C}$-pesticides residues in soil, plants and food, Panel Proc Series, STI/PUB/724, IAEA, Vienna, pp. 23-29.

Jaramillo R, Bowen W, Stoorvogel JJ (2000) Carbofuran presence in soil leachate, groundwater, and surface water in the potato growing area in Carchi, Ecuador. International Fertilized Development Center, CIP Program Report, Quito, Ecuador, pp. 355-360. 
Johnson S, Herman J, Mills A, Hornberger G (1999) Bioavailability and desorption characteristics of aged, non-extractable atrazine in soil. Environ Toxicol Chem 18: 1747-1754.

Kacew S, Akhtar MH, Khan SU (1996) Bioavailability of bound pesticide residues and potential toxicologic consequences - An update. Proc Soc Exp Biol Med 211: 62-68.

Kästner M, Nowak KM, Miltner A, Trapp S, Schäffer A (2014) Classification and Modelling of Nonextractable Residue (NER) Formation of Xenobiotics in Soil - A Synthesis Critical Rev. Environ Sci Technol 44: 2107-2171.

Khairatul AM, Ngan CK, Ismail BS (2013) Adsorption and leaching studies of molinate, carbofuran and propiconazole in Muda agricultural soils. J Trop Agric Fd Sc 41: 127-136.

Khan SU (1982) Bound pesticide residues in soil and plants. Residue Rev 84: 1-25.

Khan SU, Behki R (1990) Effects of Pseudomonas Species on the release of bound ${ }^{14} \mathrm{C}$ residues from soil treated with $\left[{ }^{14} \mathrm{C}\right]$ atrazine. J Agric Food Chem 38: 2090-2093.

Khan SU, Hamilton HA (1980) Extractable and bound (nonextractable) residues of prometryn and its metabolites in an organic soil. J Agric Food Chem 28: 126-132.

Khan SU, Ivarson KC (1981) Microbial release of unextracted (bound) residues from an organic soil treated with prometryn. J Agric Food Chem 29: 1301-1303.

Khan SU, Ivarson KC (1982) Release of soil bound (nonextractable) residues by various physiological groups of microorganisms. J Environ Sci Health B 17: 737-749.

Ladd JP (1989) The role of the soil microflora in the degradation of organic matter. In: Hattori Y, Ishida Y, Maruyanna Y, Morita RY, Uchida A (eds) Proc 5th Int Syrup on Microbial Ecology, Japan, Sci Soc press, pp. 169-174.

Lee YD, Lee KH, Park CK (1987) Fate of ${ }^{14} \mathrm{C}$-Carbofuran in Rice Plant and Paddy Soil. Korean J Environ Agric 6: 7-16.

Lee YD, Park CK (1995) Degradation of $\left[{ }^{14} \mathrm{C}\right]$ Carbofuran in Soils and Characterization of its Nonextractable Residues. Agric Chem Biotechnol 38: 263-268.

Lerch TZ, Dignac M-F, Nunan N, Barriuso E, Mariotti A (2009) Ageing processes and soil microbial community effects on the biodegradation of soil ${ }^{13} \mathrm{C}-2,4-\mathrm{D}$ nonextractable residues. Environ Pollut 157: 2985-93.

Lewandowska A (2004) Bound residues of ${ }^{14} \mathrm{C}-2,4-\mathrm{D}$ in the soil their significance for the environment. J Plant Protection Research 44: 111-116.

Lewandowska A, Weymann P (2002) Pobór biologiczny pozostałości ${ }^{14} \mathrm{C}-2,4-\mathrm{D}$ związanych w glebie. Prog Plant Protection/ Post Ochr Roślin 42: 769-772.

Liu J, Wang Y, Jiang B, Wang L, Chen J, Guo H, Ji R (2013) Degradation, metabolism, and bound-residue formation and release of tetrabromobiphenol A in soil during sequential anoxic-oxic incubation. Environ Sci Technol 47: 8348-8354.

Loiseau L (2001) Processus de stabilisation des pesticides dans les sols: mécanismes impliqués, caractérisation et biodisponibilité des résidus liés (ou non extractibles) de l'atrazine. PhD Thesis, Paris 6 University, Paris.

Loiseau L, Zegouagh Y, Bardoux G, Barriuso E, Derenne S, Mariotti A, Chenu C, Largeau C (2002) Study of atrazine fate in silty loamy soils of the Paris Basin via a combination of isotopic and pyrolytic methods. Bull Soc Geol de France 173: 271-279.
Nakagawa LE, Andrea M de M (2000) Release of non-extractable or bound residues of the atrazine herbicide in soil and its absorption by plants. Pesq Agropec Bras 35: 1517-1522.

Nam K, Kim JY (2002) Role of loosely bound humic substances and humin in the bioavailability of phenanthrene aged in soil. Environ Pollut 118: 427-433.

Nichiolls PH (1988) Factors influencing entry of pesticides into soil water. J Agric Food Chem 33: 567-569.

Novak JM, Jayachandran K, Moorman TB, Weber JB (1995) Sorption and binding of organic compounds in soils and their relation to bioavailability. In: Skipper HD, Turco RF (eds) Bioremediation: Science and Applications SSSA Spec Pub 43 SSSA, Madison, WI, pp. 13-31.

Nowak KM, Miltner A, Gehre M, Schäffer A, Kästner M (2011) Formation and Fate of Bound Residues from Microbial Biomass during 2,4-D Degradation in Soil. Environ Sci Technol 45: 999-1006.

Otieno PO, Lalah JO, Munir V (2012) Forensic analysis of carbofuran in vultures and environmental samples collected from Laikipia and Isiolo Districts. In: Ngaio R (ed) Carbofuran and Wildlife Poisoning: Global Perspectives and Forensic Approaches, 1st ed. Wiley and Sons, London, pp. 77-84.

Regitano JB, Koskinen WC, Sadowsky MJ (2006) Influence of soil aging on sorption and bioavailability of simazine. J Agric Food Chem 54: 1373-1379.

Roberts TR, Standen ME (1981) Further studies of the degradation of the pyrethroid insecticide cypermethrin in soils. Pestic Sci 12: $285-296$

Roberts TR, Klein W, Still GG, Kearney PC, Dresher N, Desmoras J, Esser HO, Aharonson N, Vonk JW (1984) Non-extractable pesticide residues in soils and plants. Pure Appl Chem 56: 945-956.

Saxena PN, Gupta SK, Murthy RC (2013) Comparative toxicity of carbaryl, carbofuran, cypermethrin and fenvalerate in Metaphire posthuma and Eisenia fetida - A possible mechanism. Ecotoxicol Environ Saf 100: 218-25.

Scheunert I, Reuter S (2000) Formation and release of residues of the ${ }^{14} \mathrm{C}$-labelled herbicide isoproturon and its metabolites bound in model polymers and in soil. Environ Pollut 108: 61-68.

Scribner SL, Benzing TR, Sun S, Boyd SA (1992) Desorption and bioavailability of aged simazine residues in soil from a continuous corn field. J Environ Qual 21: 115-120.

Senesi N (1992) Binding mechanisms of pesticides to soil humic substances. Sci Tot Environ 123/124: 63-76.

Thibaud MC, Bastide J, Coste CM, Cahet G (1983) Effect of application on a herbicide propyzamide into soil by study of mineralization of glucose ${ }^{14} \mathrm{C}(\mathrm{U})$ and distribution of radioactivity in various fractions of the soil (Laboratory and open field tests). J Environ Sci Health B18: 229-252.

Trabue SL, Feng X, Ogram AV, Ou LT (1997) Carbofuran degradation in soil profiles. J Environ Sci Health B32: 861-878.

Yee D, Weinberger P, Khan SU (1985) Release of soil-bound prometryne residues under different soil $\mathrm{pH}$ and nitrogen fertilizer regimes. Weed Sci 33: 882-887.

Weissenfels WD, Klewer HJ, Langhoff J (1992) Adsorption of PAHs by soil particles - influence on biodegradability and biotoxicity. Appl Microbiol Biotechnol 36: 689-696. 